\title{
Validity, Reliability and Factorial Structure of the Self Compassion Scale-Youth Version in the Greek Population
}

\author{
Eirini Karakasidou, Georgia Raftopoulou, Christos Pezirkianidis, Anastassios Stalikas \\ Panteion University, Athens, Greece \\ Email: irenekarakasidou@yahoo.com
}

How to cite this paper: Karakasidou, E., Raftopoulou, G., Pezirkianidis, C., \& Stalikas, A. (2021). Validity, Reliability and Factorial Structure of the Self Compassion Scale-Youth Version in the Greek Population. Psychology, 12, 536-553.

https://doi.org/10.4236/psych.2021.124033

Received: March 2, 2021

Accepted: April 12, 2021

Published: April 15, 2021

Copyright $\odot 2021$ by author(s) and Scientific Research Publishing Inc. This work is licensed under the Creative Commons Attribution International License (CC BY 4.0).

http://creativecommons.org/licenses/by/4.0/

(c) (i) Open Access

\begin{abstract}
The scope of the current research is to validate the Self-Compassion Scale for Youth (SCS-Y). For this study, participants $\left(N=193, M_{a g e}=11.74\right)$ were recruited online. Each participant completed a battery of self-reported questionnaires. Normality was tested by examining the distributional indices for each of the SCS-Y items. We then examined the Pearson $r$ intercorrelations of the SCS-Y items per factor. To test the predictive model in which SCS-Y items fit, we conducted a confirmatory factor analysis (CFA). Model fit indices were great: $x^{2}=1.338(<3.00)$, CFI $=0.90(\geq 0.90)$, GFI $=0.92(>0.90)$, RMSEA $=0.04(<0.08)$ and SRMR $=0.06(<0.08)$, which prove that the Greek version of SCS-Y has high construct validity. We evaluated the internal consistency of the SCS-Y factors using Cronbach's alpha $(a=0.64)$. To further examine the scale's construct validity, we examined convergent and discriminant validity by testing the correlations between other measures and scale's factor scores. The results revealed that SCS-Y is a reliable and valid psychometric instrument to measure self-compassion in Greek youth. Furthermore, it reveals that these findings extend to the children population between 8 and 14 years old and suggest an imperative focus for future research and intervention.
\end{abstract}

\section{Keywords}

Self-Compassion, Youth, Positive Psychology, Greek Validation, Reliability, Validity, Psychometric Properties

\section{Introduction}

Positive Psychology, introduced by Martin Selingman in 1998, consists of a 
scientific and structured psychology field that investigates people's thoughts, actions, processes and resources that make them flourish. Self-compassion is a relatively recent concept in Positive Psychology. It has its origins in Eastern philosophy and, more specifically, to Buddhist philosophy, which dates back centuries (Davidson \& Harrington, 2002). Neff (2003a) was the first to define self-compassion and introduce it in the psychological literature. According to Neff (2003a), self-compassion refers to an attitude of warmth and acceptance towards the self's sides in moments of vulnerability or failure. The individual's difficulty may relate to personal weaknesses, failures, or painful external conditions (Neff, 2009). Self-compassion refers to a healthy, balanced relationship towards oneself, seeing things in their proper dimension when struggling. In other words, with increased self-kindness, common humanity and mindfulness and reduced self-judgment, isolation, and overidentification (Neff, 2016).

These six dimensions constitute the essential components of self-compassion. More specifically, self-kindness is about behaving with a kind, understanding and supportive attitude towards oneself in a hard time (Neff, 2003a). The individual adopts this attitude towards all aspects of himself, his behaviours, feelings and thoughts (Gilbert \& Irons, 2004). Kindness contrasts with the critical attitude towards self, which includes a hostile, derogatory, critical attitude towards the self, rejecting aspects of the self and its overall value (Neff, 2003b).

Common humanity refers to experiencing negative experiences as a universal phenomenon. Considering the negative aspects of the human experience involves recognising that all people have flaws, make mistakes and fail. Thus a defective state of the individual is linked to human existence in general. This view includes recognising the individual's connection to others and a sense of awareness of common human nature in moments of sadness and weakness. This characteristic contrasts with isolation, through which the individual perceives his negative experience as something separate and isolated (Neff, 2003b).

Mindfulness is about being aware of painful thoughts and feelings in the present moment (Barnard \& Curry, 2011; Neff, 2003a). Mindfulness refers to the awareness, attention and acceptance of the individual's experience in the present moment and the recognition and understanding of his emotions in a balanced way (Shapiro, Brown, \& Biegel, 2007). This feature contrasts with two other situations. One is avoidance, in which the individual ignores and avoids painful experiences, thoughts and feelings (Neff, 2003b). The other is ruminating and magnifying the negative aspects of self or life. When this happens, individuals are so absorbed in their current emotional reactions that they cannot reach the other side of themselves (Gilbert \& Procter, 2006; Neff \& Vonk, 2009). Mindfulness is the middle ground between the two. Individuals do not suppress or deny painful emotions, nor do they dramatise them, but recognise and accept the negative experience.

The three aspects of self-compassion are conceptually different. They are experienced differently on a phenomenological level, yet they interact and rein- 
force each other (Neff, 2003a). The greater the awareness, the easier it is to understand the universal dimension of one's problems. Research shows that self-compassion is positively associated with positive emotions (Neff, Rude, \& Kirkpatrick, 2007), subjective happiness, and life satisfaction (Heffernan, Griffin, McNulty, \& Fitzpatrick, 2010; Neff, 2011; Neff \& Costigan, 2014). Overall, approaching painful situations in a self-compassionate way seems to facilitate self and relationship with others (Neff, Kirkpatrick, \& Rude, 2007).

Much of the literature looked at similar situations in different population groups by age, geography, or other criteria. Yarnell and Neff (2013) researched adolescents' well-being and their ability to express their needs. Results showed that self-compassion is a suitable tool for highlighting adolescents' needs. It seems to help to adopt a more authentic attitude than them. Smeets, Neff, Alberts and Peters (2014) supported that increasing young female students' self-compassion led to increased awareness, optimism, self-efficacy, and a reduction in intense criticism self-flagellation. Bluth and Blanton (2014) highlighted the protective role of self-compassion in adolescents' stress and depressive symptoms. Bluth, Roberson and Gaylord (2015) implemented in adolescents an Awareness-Self-compassion pilot program to reduce stress. Jativa and Cerezo (2014) showed that self-compassion plays a mediating role between victimisation and psychological adjustment. It is also associated with reduced internalisation of adolescents who reported falling victim to school bullying.

Studies in seniors have shown significant self-compassion benefits in this age group (Allen, Goldwasser, \& Leary, 2012). Initially, it seems that self-compassion is associated with high levels of well-being and a better understanding of difficult life experiences (Allen \& Leary, 2010). High self-compassion levels also appeared to be associated with a healthier attitude toward average age changes due to middle-aged, middle-aged women (Brown, Bryant, Brown, Bei, \& Judd, 2015). Finally, research shows that people who report higher self-compassion levels tend to adapt better to stressful situations (Homan, 2016; Perez-Blasco, Sales, Meléndez, \& Mayordomo, 2016).

Regarding anxiety and depression, Pauley and McPherson (2010) found that self-compassion helps people cope better with related problems, while Raes (2010) found similar results. Raes (2011) found that self-compassion may be a predictor of the development of depression, with other studies reaching similar conclusions (Krieger, Altenstein, Baettig, Doerig, \& Holtforth, 2013).

As the results of the above research show, self-compassion lists a significant number of benefits to people's mental health. Thus, there is a need to look for ways to develop self-compassion or even create programs designed to train people to be more compassionate towards themselves. In 2013, Neff and Germer created a program to develop self-compassion and awareness (Mindful-SelfCompassion Program. Karakasidou and Stalikas (2017) implemented two training self-compassion programs in Greece. Finally, another study was conducted in the Greek population to investigate the effectiveness of a short psychoeduca- 
tional program of self-compassion (Mantelou \& Karakasidou, 2017). The results were encouraging, reinforcing the findings of the research.

Neff and her partners (2021) developed the Self-Compassion Scale for Youth to measure self-compassion. The original scale was constructed for adults. The original Self-Compassion Scale for Youth has 17 items measuring six self-compassion components: Self-kindness, self-judgment, common humanity, isolation, mindfulness and over-identification.

Self-compassion has received increased research attention lately, and many validation studies have been conducted in different studies. This paper aimed to evaluate the psychometric properties of the Self-Compassion Scale for youth in a Greek population. This study investigates the Greek version of the self-compassion scale's psychometric properties in a wide sample of young participants. To our knowledge, this is the first SCS-Y's validation in another language, so no relevant studies have been included.

\section{Materials and Methods}

\subsection{Participants and Procedure}

Snowball sampling was used to recruit teachers in Greece who invited students and their parents to participate in the study. Teachers and parents were also recruited online. An advert was posted on Social Media. The present data were collected during 2020, from January to May. The sample consisted of 193 Greek children ( 99 boys, 51.3\%, 94 girls, 48.7\%), ageing from 8 to 14 years old. The mean age for the total sample was Mage $=11.74, S D=2.01$, for boys, Mage = $11.78, S D=12.04$ and girls, Mage $=11.69, S D=1.99$. In terms of self-reported ethnicity: $100 \%$ were White. Most $(89.2 \%)$ reported Greek as their first language. The researchers did not collect information about socioeconomic status, as most youths often have inaccurate knowledge of their family's SES. However, participants were drawn from socio-economically diverse schools in Greece. To examine the convergent and divergent validity of the test, participants also filled in other scales. The current study involves children. Therefore, all participants and their parents were informed about the study's purpose and gave their informed consent. The study followed the Ethics research guidelines of the Hellenic Psychological Society. All participants completed a battery of online questionnaires.

\subsection{Translation Procedure}

The researchers used forward-backwards translation (Yu et al., 2004). The translation involved the authors and two independent translators. First, they forward translated the scale from the original language (English) to the intended language (Greek). Then, the intended language (Greek) was translated back into the original language (English). They compared the final product to the original version. Through the procedure of backward translations, inaccuracies in the intended language are identified (see also Wang et al., 2006). Finally, inaccuracies were noted and were retranslated until full agreement. 


\subsection{Measures}

Self-compassion Scale for youth: The Greek SCS-Y has 17-item. The SCS includes the 3 item Self-Kindness subscale, the 3-item Self-Judgment subscale, the 3-item Common Humanity subscale, the 3-item Isolation 3-item Mindfulness subscale and the 2-item Over-Identification subscale. Responses range from "1-Almost Never" to "5-Almost Always". Mean scores on the six subscales are then averaged (after reverse-coding negative items) to create an overall self-compassion score. Higher scores correspond to higher levels of self-compassion. In the current research, internal consistency reliability was found to be $\alpha=0.64$.

Life Satisfaction Scale: (LSC; Diener, Emmons, Larsen, \& Griffin, 1985; Greek version: Stalikas \& Lakioti, 2012). The Life Satisfaction Scale investigates the estimation of a person's quality of life according to their criteria. It compromises five items rated on a 7 -point Likert scale $(1=$ Strongly Disagree-7 = Strongly Agree). The scale showed good internal consistency $(\alpha=0.86)$.

Brief Resilience Scale: The Brief Resilience Scale (BRS, Smith, Dalen, Wiggins, Tooley, Christopher, \& Bernard, 2008; Greek version: (Kyriazos, Stalikas, Prassa, Galanakis, Yotsidi, \& Lakioti, 2018) measures one's ability to recover from stress and adversity. It compromises six items, rated on a 5-point Likert scale from Strongly Disagree (1) to Strongly Agree (5). Higher scores indicate more resilience. Half of the items are reversed scored to avoid social desirability response bias. In this study, Cronbach's $\alpha$ was $\alpha=0.62$.

SPANE Scale: The Scale of Positive and Negative Experience (SPANE; Diener et al., 2010) compromises 12 items, six a to assess positive feelings and six to assess negative feelings, such as "Good", "Unpleasant", "Sad" and "Contented". It is scored in a 5-point Likert-type scale, and three subscales can be calculated, two for positive and negative experiences and one for a balance between them. Higher scores suggest a higher frequency of positive and negative emotions and also for balance. SPANE is reported to have good psychometric qualities, and in this study, Cronbach's $\alpha=0.85$ for positive emotions and $\alpha=0.80$ for negative emotions.

STAI Questionnaire: The State-Trait Anxiety Inventory for children consists of 40 items, which relate to-state anxiety and trait anxiety (STAIC, 40 items), (STAIC; Spielberg, Edwards, Lushene, Montuori, \& Platzek, 1973). The score is the sum of the points for each subscale. The answers are given on a scale of 4 grades $(1=$ not at all, $2=$ little, $3=$ moderate, $4=$ very much. The questionnaire has been standardised in the Greek sample population by Psychountaki, Zervas, Karteroliotis, \& Spielberg, 2003). In this study, the internal consistency was a = 0.73 .

SHS Scale: The Subjective Happiness Scale documents a subjective perception of happiness, as the individual experiences (SHS, four items, $\alpha=0.94$ ) (Lyubomirsky \& Lepper, 1999). The Cronbach alpha was $\alpha=0.62$. It has been standardised in Greece by Karakasidou, Pezirkianidis, Stalikas and Galanakis (2016). Its four items are rated on a 7-point Likert scale, with the lowest scores indicating 
not a very happy person and highest scores showing a very happy person.

Depression Anxiety Stress Scales-21: (DASS-21; Lovibond \& Lovibond 1995; Greek version: Stalikas \& Flora, 2012). The DASS-21 measures three negative emotional states (seven items per scale): 1) depression, 2) anxiety, and 3) tension/stress. Respondents report the presence of 21 symptoms over the previous week using a 4-point Likert-type scale (1-Did not apply to me at all to 4-Applied to me very much or most of the time). The scale demonstrated very high internal consistency ( $\alpha=0.89$ ).

\subsection{Statistical Analysis}

The data were analysed using the Statistical Package for the Social Sciences vol. 21 and the IBM SPSS Amos, version 21.

Item analysis and normality testing. First of all, normality was tested by examining the distributional indices for each of the SCS-Y items. Cohen, Cohen, West, and Aiken (2002) suggest cut-off scores of less than 2 for skewness and less than 7 for kurtosis.

Inter-item correlations. We then examined the Pearson $r$ intercorrelations of the SCS-Y items per factor according to Neff and colleagues (2021). Correlations between 0.20 and 0.40 would indicate reasonable item homogeneity. Correlations less than 0.20 would be indicative of items that load at different factors and higher than 0.40 would suggest that the two items do not capture an ample width of the variance of the specific factor, in which they load (Piedmont, 2014).

Confirmatory factor analysis. To test the predictive model in which SCS-Y items fit, we conducted a confirmatory factor analysis (CFA) using the IBM SPSS AMOS, version 21. Thus, we created a model based on Neff and colleagues (2021) model of six factors that load to a higher-order self-compassion factor and a model of six first-order correlated factors based on previous studies (see Karakasidou \& Stalikas, 2017). Preliminarily, Mardia's test of multivariate normality and Mahalanobis d-squared statistic were examined (Hair, Black, Babin, \& Aderson, 2010). Different fit indices were used to assess model fit: $\mathrm{x}^{2}$ ratio $\left(\mathrm{x}^{2} /\right.$ degrees of freedom), the root-mean-square error of approximation (RMSEA; Browne \& Kudeck, 1993), the standardised root-mean-square residual (SRMR; Hu \& Bentler, 1995), the comparative fit index (CFI; Bentler, 1990), and the Goodness of Fit Index (GFI; Jöreskog, \& Sörbom, 1996). Cut-off scores are based on $\mathrm{Hu}$ and Bentler (1999) suggestions for model fit: $\mathrm{x}^{2}$ values less than 3 , RMSEA and SRMR values less than .08, and CFI and GFI values higher than .90 indicate good model fit.

Internal consistency reliability. We evaluated the internal consistency of the SCS-Y factors using Cronbach's alpha. Values higher than 0.70 indicate good internal consistency (DeVellis, 2012; Kyriazos, 2017).

Convergent and discriminant validity. To further examine the scale's construct validity, we examined convergent and discriminant validity by testing the correlations between other measures and scale's factor scores. Positive correla- 
tions with similar constructs would be indicative of convergent validity and negative or non-correlation with totally different constructs would indicate discriminant validity.

\section{Results}

\subsection{Item Analysis and Normality Testing}

To examine item quality and the probability of dysfunctional items or polarisation, we estimated the variances, means and standard deviations of the 17 SCS-Y items. We expected variances ranging from 1 to 2.5 , indicative of a normal distribution regarding the given answers (reports of self-compassion were rated on a 5-point scale). Moreover, we were expecting means ranging from 2 to 3.5 , also indicative of a normal distribution. Results indicate that all items have a normal distribution. Means were ranging from 2.47 to 3.59, standard deviations from 1.280 to 1.472 and variances from 1.638 to 2.166, as expected. Also, we computed skewness and kurtosis values for SCS-Y items (see Table 1). They were less than 2 for every item.

Table 1. Distributional indices of the SCS-Y items $(N=183)$.

\begin{tabular}{|c|c|c|c|c|c|c|c|}
\hline Item No. & Subscale & Mean & $S E$ & $S D$ & Var & Skewness & Kurtosis \\
\hline 1 & SK1 & 3.59 & 0.10 & 1.41 & 1.97 & -0.59 & -1.00 \\
\hline 2 & IS1 & 2.48 & 0.09 & 1.31 & 1.71 & 0.45 & -0.92 \\
\hline 3 & SJ1 & 2.66 & 0.10 & 1.40 & 1.95 & 0.35 & -1.08 \\
\hline 4 & $\mathrm{CH} 1$ & 2.81 & 0.10 & 1.37 & 1.88 & 0.16 & -1.19 \\
\hline 5 & OI1 & 2.91 & 0.10 & 1.36 & 1.85 & 0.10 & -1.19 \\
\hline 6 & M1 & 3.12 & 0.10 & 1.35 & 1.83 & -0.09 & -1.24 \\
\hline 7 & $\mathrm{SJ} 2$ & 2.56 & 0.10 & 1.33 & 1.78 & 0.38 & -1.01 \\
\hline 8 & $\mathrm{CH} 2$ & 2.72 & 0.10 & 1.39 & 1.93 & 0.21 & -1.23 \\
\hline 9 & SK2 & 2.98 & 0.10 & 1.35 & 1.82 & -0.04 & -1.17 \\
\hline 10 & IS2 & 2.47 & 0.09 & 1.29 & 1.66 & 0.42 & -0.96 \\
\hline 11 & M3 & 3.05 & 0.10 & 1.35 & 1.82 & -0.21 & -1.13 \\
\hline 12 & SJ3 & 2.75 & 0.09 & 1.28 & 1.64 & 0.25 & -1.05 \\
\hline 13 & CH3 & 3.10 & 0.11 & 1.47 & 2.17 & -0.04 & -1.43 \\
\hline 14 & OI2 & 2.88 & 0.10 & 1.39 & 1.93 & 0.10 & -1.23 \\
\hline 15 & SK3 & 3.32 & 0.09 & 1.29 & 1.67 & -0.34 & -0.93 \\
\hline 16 & IS3 & 2.56 & 0.10 & 1.39 & 1.94 & 0.45 & -1.04 \\
\hline 17 & M2 & 2.97 & 0.10 & 1.38 & 1.92 & -0.06 & -1.25 \\
\hline
\end{tabular}

Note. $S D=$ standard deviation, $S E=$ standard error of mean, $V a r=$ variance. 


\subsection{Inter-Item Correlations}

To further examine item quality, we carried out a correlational analysis between the items that belong to the six factors of self-compassion (see Table 2) identified by Neff (2003a) and confirmed for the SCS-Y by Neff and her colleagues (2021). We were expecting to find positive statistically significant correlations between the items ranging from 0.20 to 0.40 .

Self-Kindness inter-item correlations ranged from 0.30 to 0.41 , Self-Judgment from 0.20 to 0.27 , Common Humanity from 0.22 to 0.42 , Isolation from 0.24 to 0.38 , Mindfulness from 0.28 to 0.49 and Overidentification inter-item correlations were 0.33 . The above inter-item correlations were significant $(p<0.001)$. Overall, almost all items of each factor showed correlations ranging from 0.20 to 0.40 , which is indicative of high item redundancy, apart from two Mindfulness items. More specifically, M1 and M3 showed higher correlation $(r=0.49)$, indicating that these items capture a smaller width of the factor variance. The above findings are indicative of adequate construct validity.

Table 2. SCS-Y inter-item correlations $(N=183)$.

\begin{tabular}{|c|c|c|c|c|c|c|c|c|c|c|c|c|c|c|c|c|c|}
\hline I\# & 1 & 2 & 3 & 4 & 5 & 6 & 7 & 8 & 9 & 10 & 11 & 12 & 13 & 14 & 15 & 16 & 17 \\
\hline 1 & 1 & & & & & & & & & & & & & & & & \\
\hline 2 & 0.09 & 1 & & & & & & & & & & & & & & & \\
\hline 3 & 0.03 & $0.41^{\star *}$ & 1 & & & & & & & & & & & & & & \\
\hline 4 & $0.30^{* * *}$ & $0.18^{\star}$ & $0.17^{*}$ & 1 & & & & & & & & & & & & & \\
\hline 5 & 0.13 & $0.30^{* * *}$ & $0.28^{* * *}$ & $0.31^{* * *}$ & 1 & & & & & & & & & & & & \\
\hline 6 & $0.33^{* * *}$ & 0.02 & 0.05 & $0.21^{* *}$ & 0.10 & 1 & & & & & & & & & & & \\
\hline 7 & 0.04 & $0.21^{\star *}$ & $0.28^{* * *}$ & 0.11 & 0.09 & 0.07 & 1 & & & & & & & & & & \\
\hline 8 & $0.17^{\star}$ & 0.12 & $0.17^{*}$ & $0.22^{* *}$ & $0.19^{* *}$ & 0.14 & $0.18^{*}$ & 1 & & & & & & & & & \\
\hline 9 & $0.30^{* * *}$ & -0.08 & 0.00 & $0.26^{* * *}$ & 0.11 & $0.20^{* *}$ & -0.09 & $0.25^{\star * *}$ & 1 & & & & & & & & \\
\hline 10 & 0.05 & $0.38^{\star * *}$ & $0.38^{\star * *}$ & 0.04 & $0.24^{* \star *}$ & -0.02 & $0.29^{\star * *}$ & $0.24^{\star * *}$ & -0.04 & 1 & & & & & & & \\
\hline 11 & $0.39^{* * *}$ & 0.06 & -0.08 & 0.09 & 0.03 & $0.49^{* * *}$ & -0.04 & $17^{\star}$ & $0.23^{* *}$ & 0.01 & 1 & & & & & & \\
\hline 12 & 0.14 & $0.16^{*}$ & $0.20^{* *}$ & 0.12 & $0.17^{\star}$ & 0.06 & $0.23^{* * *}$ & 0.08 & -0.03 & $0.31^{\star \star *}$ & -0.01 & 1 & & & & & \\
\hline 13 & $0.17^{\star}$ & $0.15^{*}$ & $0.16^{* *}$ & $0.42^{\star * *}$ & $0.21^{\star *}$ & $0.33^{\star * *}$ & 0.06 & $0.29^{\star * *}$ & $0.29^{\star * *}$ & 0.11 & $0.24^{* * *}$ & 0.12 & 1 & & & & \\
\hline 14 & 0.08 & $0.22^{\star \star}$ & $0.23^{\star * *}$ & 0.07 & $0.33^{* * *}$ & $0.17^{\star}$ & $0.16^{*}$ & 0.08 & 0.03 & $0.26^{\star * *}$ & $0.15^{\star}$ & $0.25^{\star * \star}$ & $0.26^{\star * *}$ & 1 & & & \\
\hline 15 & $0.37^{* * *}$ & 0.05 & 0.07 & $0.27^{* * *}$ & $0.27^{\star * *}$ & $0.26^{* * *}$ & -0.03 & $0.27^{\star}$ & $0.41^{\star * *}$ & -0.01 & $0.38^{* * *}$ & 0.02 & $0.30^{* * *}$ & 0.07 & 1 & & \\
\hline 16 & 0.03 & $0.24^{\star * *}$ & $0.31^{\star * *}$ & 0.12 & $0.25^{\star * *}$ & 0.07 & $0.24^{\star * \star}$ & $0.21^{\star \star}$ & 0.12 & $0.35^{\star * *}$ & -0.02 & $0.21^{\star *}$ & $0.24^{\star * *}$ & $0.24^{* * *}$ & 0.11 & 1 & \\
\hline 17 & $0.30^{* * *}$ & 0.08 & 0.08 & $0.22^{\star *}$ & -0.07 & $0.30^{\star * *}$ & 0.10 & $0.16^{*}$ & $0.22^{\star *}$ & -0.01 & $0.28^{* * *}$ & 0.03 & $0.22^{* *}$ & 0.05 & $0.38^{* * *}$ & 0.09 & 1 \\
\hline
\end{tabular}

Note. ${ }^{* *} p$-value $<0.001,{ }^{* *} p$-value $<0.01,{ }^{*} p$-value $<0.05$. I\# $=$ item number. 


\subsection{Reliability}

We estimated the scale reliability using the Cronbach alpha index, which was $a=$ 0.64 , while the initial validation found high internal consistency reliability levels $(a=0.85$; Neff et al., 2021). Further item analysis exploring the possibility of strengthening the scale reliability would give negative results if any of the items were deleted.

\subsection{Factor Analysis}

We first created the correlated first-order six-factor model (Model 1) using AMOS that was identifiable. We then ensured multivariate normality of the SCS-Y items using Mardia's test. Also, following the Mahalanobis $d$-squared cut-off score of 100, we found no outliers. We then tested the model fit; the extraction method was the maximum likelihood. The evaluation of the model fit indices showed that $\mathrm{x}^{2}$ ratio was 1.338 , which is lower than 3, CFI and GFI values were higher than 0.90, while RMSEA and SRMR values were less than 0.08 . These values are indicative of a good model fit (see Table 3 and Figure 1). Secondly, we created the second-order model, where the six factors load to a higher-order factor of self-compassion (Model 2). However, this model demonstrated a poor fit to the data (see Table 3).

\subsection{Convergent and Discriminant Validity Analysis}

To further examine the scale's validity, we tested convergent and discriminant validity by examining the correlations between SCS-Y factors and other constructs. More specifically, we tested convergent validity by examining the correlations of SCS-Y positive factors among them and with life satisfaction, resilience, positive emotions, positivity and subjective happiness. In contrast, their correlations with SCS-Y negative factors, depression, state and trait anxiety, stress, and negative emotions were tested for discriminant validity. On the other hand, the convergent validity of SCS-Y negative factors was tested by examining their correlations with other negative constructs. In contrast, for their discriminant validity, we tested their correlations with SCS-Y positive factors and other positive constructs (see Table 4).

The results indicate that SCS-Y factors have satisfactory construct validity. More specifically, SCS factors have good convergent validity, since the three negative factors that indicate self-criticism (self-judgement, isolation and overidentification) showed statistically significant low to moderate positive correlations to experiencing of negative emotions ( $r=0.19$ to 0.22$)$, stress $(r=0.21$ to $0.25)$, depression $(r=0.19$ to 0.30$)$, trait anxiety $(r=0.30$ to 0.36$)$ and state anxiety ( $r=0.18$ to 0.25$)$; the negative factors also showed zero to moderate negative correlation to experiencing of positive emotions $(r=-0.11$ to -0.21$)$, positivity $(r=-0.17$ to -0.31$)$, subjective happiness $(r=-0.12$ to -0.17$)$, life satisfaction $(r=-0.04$ to -0.16$)$, and resilience $(r=-0.23$ to -0.36$)$, which are indicative of adequate discriminant validity. 
Table 3. Fit indices in confirmatory factor analysis for the SCS-Y $(N=183)$.

\begin{tabular}{cccccccc}
\hline & $\boldsymbol{x}^{2}$ & $\boldsymbol{d f}$ & $\boldsymbol{x}^{2} / d f$ & GFI & CFI & RMSEA & SRMR \\
\hline Model 1 & $139.182^{*}$ & 104 & 1.338 & 0.92 & 0.90 & 0.04 & 0.06 \\
Model 2 & $322.311^{*}$ & 119 & 2.708 & 0.79 & 0.43 & 0.10 & 0.11 \\
\hline
\end{tabular}

Note. ${ }^{*} p$-value $<0.001 . d f=$ degrees of freedom, $\mathrm{CFI}=$ comparative fit index, GFI $=$ goodness of fit index, RMSEA $=$ root mean square error of approximation, $\mathrm{SRMR}=$ standardised root mean square residual. Extraction method: maximum likelihood.

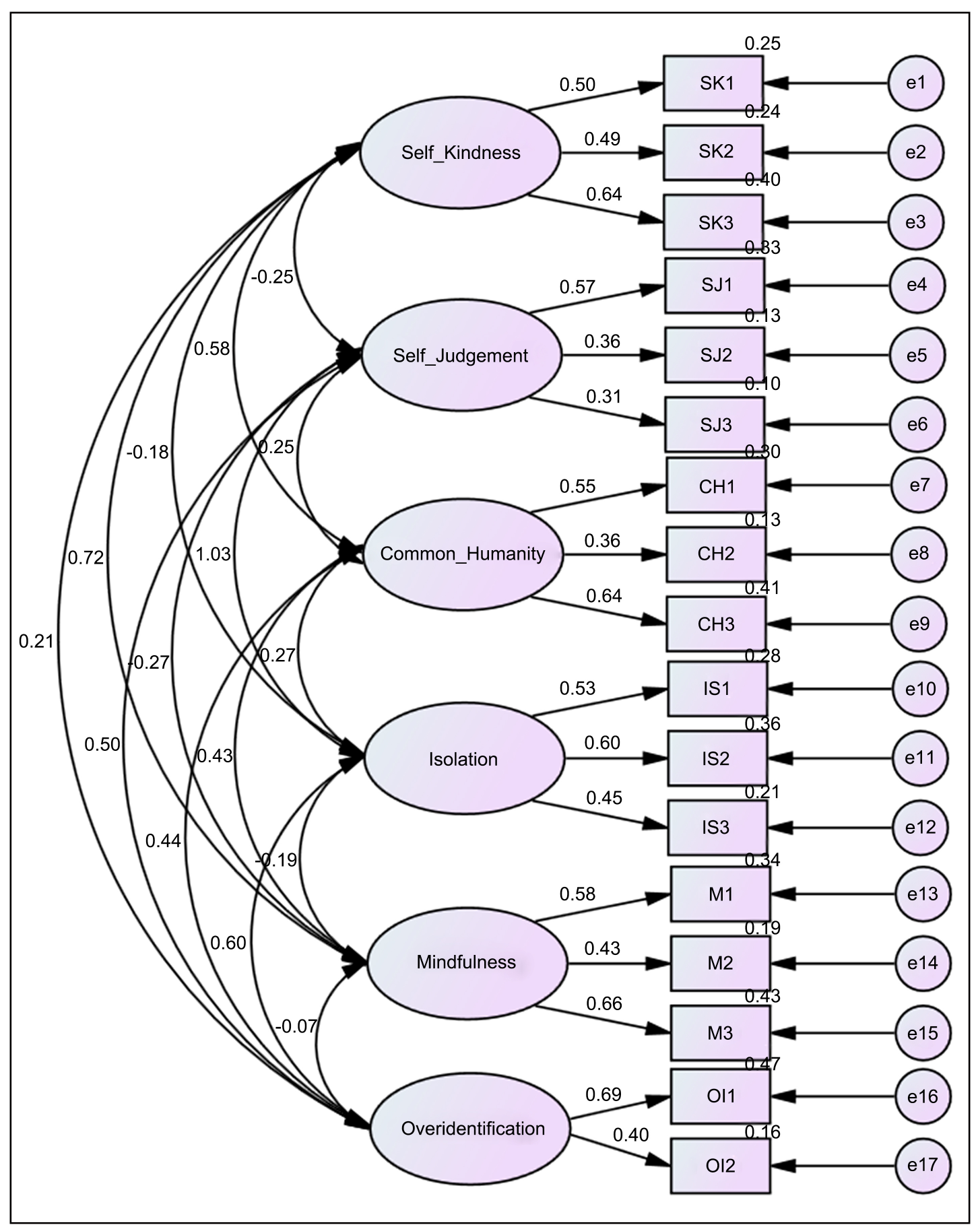

Figure 1. Standardised solution of the six-factor model of the Greek version of SCS-Y. 
Table 4. Convergent and discriminant validity of the SCS-Y $(N=183)$.

\begin{tabular}{|c|c|c|c|c|c|c|c|}
\hline & SK & SJ & $\mathrm{CH}$ & I & $\mathbf{M}$ & OI & SC \\
\hline Self-kindness & 1 & & & & & & \\
\hline Self-judgement & $-0.15^{*}$ & 1 & & & & & \\
\hline Common Humanity & $0.33^{\star * *}$ & 0.12 & 1 & & & & \\
\hline Isolation & -0.09 & $0.47^{\star * *}$ & $0.19^{*}$ & 1 & & & \\
\hline Mindfulness & $0.43^{* * *}$ & -0.11 & $0.25^{* * *}$ & -0.10 & 1 & & \\
\hline Overidentification & 0.05 & $0.24^{* * *}$ & $0.21^{\star *}$ & $0.34^{\star * *}$ & -0.02 & 1 & \\
\hline Self-compassion & $0.61^{* * *}$ & $-0.56^{\star * *}$ & $0.34^{* * *}$ & $-0.57^{\star * *}$ & $0.61^{* * *}$ & $-0.46^{* * *}$ & 1 \\
\hline Trait anxiety & $-0.25^{\star \star *}$ & $0.30^{* * *}$ & 0.09 & $0.36^{\star * *}$ & $-0.24^{\star * *}$ & $0.32^{\star * \star}$ & $-0.44^{\star * *}$ \\
\hline State anxiety & -0.05 & $0.18^{\star}$ & $0.21^{\star \star}$ & $0.25^{\star * \star}$ & -0.12 & $0.21^{* *}$ & $-0.19^{\star *}$ \\
\hline Depression & -0.11 & $0.19^{* *}$ & 0.12 & $0.30^{\star * *}$ & -0.13 & $0.24^{\star * *}$ & $-0.27^{\star * *}$ \\
\hline Stress & -0.08 & $0.21^{* *}$ & $0.15^{\star}$ & $0.25^{\star * \star}$ & -0.13 & $0.22^{* *}$ & $-0.23^{\star * *}$ \\
\hline Negative emotions & $-0.29^{\star * *}$ & $0.22^{\star *}$ & 0.04 & $0.25^{\star * *}$ & $-0.19^{\star *}$ & $0.19^{* *}$ & $-0.35^{\star * *}$ \\
\hline Positive emotions & $0.38^{\star * *}$ & $-0.21^{\star *}$ & 0.12 & -0.11 & $0.39^{* \star *}$ & -0.14 & $0.42^{\star * \star}$ \\
\hline Positivity & $0.38^{\star * *}$ & $-0.31^{\star * *}$ & 0.01 & $-0.26^{\star * *}$ & $0.32^{\star * *}$ & $-0.17^{\star}$ & $0.45^{\star * \star}$ \\
\hline Life satisfaction & $0.35^{\star * *}$ & $-0.16^{*}$ & 0.01 & -0.14 & $0.27^{\star * *}$ & -0.04 & $0.30^{* * *}$ \\
\hline Subjective happiness & $0.32^{\star * *}$ & $-0.15^{*}$ & 0.06 & $-0.17^{\star}$ & $0.31^{\star * *}$ & -0.12 & $0.36^{* * *}$ \\
\hline Resilience & $0.27^{\star * *}$ & $-0.23^{\star *}$ & -0.10 & $-0.31^{\star \star \star}$ & $0.24^{* * *}$ & $-0.36^{\star * *}$ & $0.42^{* * *}$ \\
\hline
\end{tabular}

Note. ${ }^{* * *} p$-value $<0.001,{ }^{* *} p$-value $<0.01,{ }^{*} p$-value $<0.05 . \mathrm{SK}=$ Self-Kindness, $\mathrm{SJ}=$ Self-Judgement, $\mathrm{CH}=\mathrm{Common} \mathrm{Humanity}, \mathrm{I}=\mathrm{Isolation}, \mathrm{M}=\mathrm{Mind}-$ fulness, $\mathrm{OI}=$ Overidentification, $\mathrm{SC}=$ Self-Compassion.

On the other hand, the two of the three positive factors of self-compassion (self-kindness and mindfulness) except for common humanity and the total score showed statistically significant, statistically significant low to moderate positive correlations to experiencing of positive emotions ( $r=0.38$ to 0.42 ), positivity ( $r=0.32$ to 0.45 ), subjective happiness ( $r=0.31$ to 0.36 ), life satisfaction ( $r=0.27$ to 0.35$)$, and resilience $(r=0.24$ to 0.42$)$. The positive factors apart from common humanity correlated negatively to experiencing negative emotions ( $r=-0.19$ to -0.35$)$, stress ( $r=-0.08$ to -0.23 ; only the correlation with the total score was statistically significant), depression $(r=-0.11$ to -0.27 ; only the correlation with the total score was statistically significant), trait $(r=-0.24$ to -0.44$)$ and state anxiety ( $r=-0.05$ to -0.19 ; only the correlation with the total score was statistically significant), which indicates adequate discriminant validity. However, the common humanity factor was found to correlate positively with stress $(r=0.15)$, state anxiety $(r=0.21)$, and with both positive and negative factors of SCS-Y.

\subsection{Normative Data}

Means, standard deviations, ranges and percentiles were computed for the SCS-Y factors to assist mental health professionals in deeply understand and better interpret its scores (see Table 5). 
Table 5. Descriptive statistics and normative data for SCS-Y factors $(N=183)$.

\begin{tabular}{cccccccccccc}
\hline & Mean & SD & Range & $\mathbf{5}$ & $\mathbf{1 0}$ & $\mathbf{2 5}$ & $\mathbf{5 0}$ & $\mathbf{7 5}$ & $\mathbf{9 0}$ & $\mathbf{9 5}$ \\
\hline SK & 3.36 & 0.95 & 3.67 & 1.67 & 2.00 & 2.67 & 3.33 & 4.00 & 4.67 & 4.67 \\
SJ & 2.68 & 0.89 & 4.00 & 1.33 & 1.67 & 2.00 & 2.67 & 3.33 & 3.67 & 4.33 \\
CH & 2.92 & 0.99 & 4.00 & 1.33 & 1.67 & 2.33 & 2.67 & 3.67 & 4.33 & 4.67 \\
I & 2.52 & 0.95 & 4.00 & 1.00 & 1.00 & 2.00 & 2.67 & 3.33 & 3.67 & 4.00 \\
M & 3.09 & 0.97 & 4.00 & 1.40 & 1.67 & 2.33 & 3.00 & 3.67 & 4.33 & 4.67 \\
OI & 2.93 & 1.08 & 4.00 & 1.00 & 1.50 & 2.00 & 3.00 & 4.00 & 4.50 & 4.50 \\
SC & 3.21 & 0.50 & 2.64 & 2.33 & 2.66 & 2.86 & 3.19 & 3.52 & 3.80 & 4.16 \\
\hline
\end{tabular}

Note. Percentiles provided: 5, 10, 25, 50, 75, 90, 95.

\section{Discussion}

The purpose of the current research was to validate the psychometric properties of The Self-Compassion Scale for Youth (Neff et al., 2021) in a sample of Greek children. According to the literature review, Neff and her colleagues conducted studies to investigate the benefits of self-compassion on adolescents. It has been proven that self-compassion encourages adolescents to adopt an authentic attitude (Yarnell \& Neff, 2013), increasing the levels of awareness, self-efficacy, and optimism while decreasing self-criticism self-flagellation (Smeets et al., 2014). Self-compassion has also been found to protect adolescents from depression and stress (Bluth \& Blanton, 2014).

The original SCS-Y consists of 17 items, which measures the whole self-compassion. The items load to six factors, which load self-compassion components (self-kindness, self-criticism, common humanity, isolation, mindfulness, over-identification). Responses are given to a 5-point Likert scale, ranging from $1=$ Almost Never to $5=$ Almost Always (Neff et al., 2021).

Results showed that the Greek version of the SCS-Y presents good validity and reliability. Therefore, it should be considered a reliable instrument in measuring self-compassion in Greek youths. Firstly, the variance among items was examined to detect possible problematic items or polarisation. According to the results, there were no dysfunctional items, as all items have a normal distribution ranging from 1.64 to 2.17 (variance). Also, the mean scores range from 2.47 to 3.59 and the standard deviations from 1.28 to 1.47 . Skewness values range from -0.59 to 0.45 , and Kurtosis values range from -1.43 to -0.92 , which are both below 2, so they were acceptable.

The next step was to calculate the inter-item correlations, which showed adequate construct validity. Inter-item correlations ranged from 0.30 to 0.41 for self-kindness, 0.20 to 0.27 for self-judgment, from 0.22 to 0.42 for common humanity, from 0.24 to 0.38 for isolation, from 0.28 to 0.49 for mindfulness and 0.33 for overidentification and the significance was $p<0.001$ for all the inter-item correlations. 
Reliability was tested using Cronbach alpha, and the index was 0.64. This index is lower than the original scale's index ( $a=0.85$; Neff et al., 2021). As the index was not satisfactory enough, further steps were calculated to test if the Cronbach alpha index would have given a higher index if items deleted. Nevertheless, no satisfactory results were found. One explanation is that the current research sample consisted of 193 children aged 8 to 14 years old, so the age deviation was big.

CFA was conducted to test the six-factor model fit. Mardia's test ensured the multivariate normality, and Mahalanobis $d$ showed no outliers. Model fit indices were great: $\mathrm{x}^{2}=1.338(<3.00), \mathrm{CFI}=0.90(\geq 0.90), \mathrm{GFI}=0.92(>0.90), \mathrm{RMSEA}=$ $0.04(<0.08)$ and SRMR $=0.06(<0.08)$, which prove that the Greek version of SCS-Y has high construct validity. The original scale was also constructed using ESEM and CFA models with similar fit indices, which proved well-defined factors (Neff et al., 2021). On the other hand, Model 2 showed poor fit data. Maybe a larger sample ( $\mathrm{N}>200$ participants) would have shown good fit data.

Also, convergent and discriminant validity analysis was conducted to examine the scale's validity further. The positive subscales were correlated with positive variables, like life satisfaction, resilience, positive emotions, positivity and subjective happiness. The results show low to moderate positive correlations except for the subscale of common humanity. The two positive scales were also negatively correlated with experiencing negative emotions, stress, depression, trait anxiety and state anxiety. On the other hand, the three negative subscales were positively correlated with the negative variables (zero to moderate). They were negatively correlated with the positive variables, like life satisfaction.

Contrary to the expected results, the common humanity factor correlates positively with stress, state anxiety and the negative factors of SCS-Y. In contrast, it was expected to have been negatively correlated with the above factors. According to Ozlem, Sahin-Baltaci, \& Karatas (2017), common humanity differs from the other two variables regarding the acceptance of pain and negative emotions as a situation that all people experience in their lives. On the other hand, self-kindness refers to the kind attitude one has for itself, while mindfulness refers to the present-awareness of painful thoughts and feelings. Ozlem et al. (2017) have found that only the common humanity factor predicts counselling help-seeking, as the individual recognises the pain as a universal phenomenon. Hence, it is easier to talk about its negative thoughts and feelings. Acknowledging pain as a universal phenomenon does not necessarily mean that the pain is reduced because the individual may evaluate it as something inevitable and that all people suffer from it.

The current results are explained exclusively by the original scale's psychometric features. There were no other published translated versions of SCS-Y to compare our results.

One limitation of the study was the reliability, which was not satisfactory enough. Further studies should be conducted, including a larger number of the 
sample without big age differences. One second limitation was that the reliability was tested using Cronbach alpha, so further studies should examine test-retest reliability. Researchers should also investigate the psychometric properties of the SCS-Y worldwide since it is essential to consider possible cultural differences. The Greek version was not likely to be compared with other versions rather than the original one since the SCS-Y has not been adapted/adjusted yet to other foreign populations. Since the Greek version of SCS-Y showed good psychometric properties, Greek researchers should leverage it in studies to study the benefits of self-compassion on Greek youths. Finally, future research may investigate the construct of a Self-Compassion Scale for Greek adolescents. The current study collected data from children aged 8 to 14 .

Despite the limitations, the results showed that SCS-Y is a valid and reliable psychometric instrument. As self-compassion is a taught construct, this tool could help measure interventions' efficacy in youth. Thus, relevant interventions could be designed, implemented and investigated. During childhood and adolescence, young people shape their personality. Still, this period of human life seems to affect mental health during emerging adulthood and throughout adulthood. Self-compassion appears to be a healthy and balanced way for a person to relate to himself. Research shows that high self-compassion levels are associated with self-esteem, self-efficacy, and well-being (Smeets et al., 2014).

On the other hand, high self-compassion levels lead to lower levels of anxiety, stress and depression (Bluth \& Blanton, 2014). Therefore, self-compassion interventions could help young people in terms of support and prevention, with positive consequences throughout their lives. The possibility of using a research-valid and reliable tool to measure self-compassion opens the horizons for further research at a development stage that has not been thoroughly investigated yet. Besides, children and adolescents need emotional support to cope with everyday life difficulties. Therefore, there seems to be a need to design and implement scientific programs to enhance youth's mental skills. Finally, research may extend to clinical or vulnerable populations.

\section{Conclusion}

The results showed that SCS-Y is a reliable and valid psychometric tool to measure self-compassion in Greek youth. In surveys, the SCS-Y would be doled in combination with other variables in order to broaden the contribution of self-compassion in youth in the field of Positive Psychology. Also, means, standard deviations, ranges and percentiles were presented in order to assist mental health professionals in understanding and interpreting in-depth the scores of its subscale, and this may help them to configure the therapeutic aims and enhance children's positive components of self-compassion (self-kindness, common humanity, mindfulness). Finally, mental health professionals and researchers should consider that SCS-Y is a psychometric tool that measures self-compassion in children and not in adolescents. 


\section{Fund}

This research is co-financed by Greece and the European Union (European Social Fund-ESF) through the Operational Programme "Human Resources Development, Education and Lifelong Learning" in the context of the project "Reinforcement of Postdoctoral Researchers-2nd Cycle" (MIS-5033021), implemented by the State Scholarships Foundation (IKY).

\section{Conflicts of Interest}

The authors declare no conflicts of interest regarding the publication of this paper.

\section{References}

Allen, A. B., \& Leary, M. R. (2010). Self-Compassion, Stress, and Coping. Social and Personality Psychology Compass, 4, 107-118. https://doi.org/10.1111/j.1751-9004.2009.00246.x

Allen, A. B., Goldwasser, E., \& Leary, M. (2012). Self-Compassion and Well-Being among Older Adults. Self and Identity, 11, 428-453. https://doi.org/10.1080/15298868.2011.595082

Barnard, L. K., \& Curry, J. F. (2011). Self-Compassion: Conceptualizations, Correlates, \& Interventions. Review of General Psychology, 15, 289-303. https://doi.org/10.1037/a0025754

Bentler, P. M. (1990). Comparative Fit Indexes in Structural Models. Psychological Bulletin, 107, 238-246. https://doi.org/10.1037/0033-2909.107.2.238

Bluth, K., \& Blanton, P. (2014). Mindfulness and Self-Compassion: Exploring Pathways to Adolescent Emotional Well-Being. Journal of Child and Family Studies, 23, 1298-1309. https://doi.org/10.1007/s10826-013-9830-2

Bluth, K., Roberson, P. N., \& Gaylord, S. A. (2015). A Pilot Study of a Mindfulness Intervention for Adolescents and the Potential Role of Self-Compassion in Reducing Stress. Explore: The Journal of Science and Healing, 11, 292-295. https://doi.org/10.1016/j.explore.2015.04.005

Brown, L., Bryant, C., Brown, V., Bei, B., \& Judd, F. (2015). Investigating How Menopausal Factors and Self-Compassion Shape Well-Being: An Exploratory Path Analysis. Maturitas, 81, 293-299. https://doi.org/10.1016/j.maturitas.2015.03.001

Browne, M. W., \& Cudeck, R. (1993). Alternative Ways of Assessing Model Fit. In K. A. Bollen, \& J. S. Long (Eds.), Testing Structural Equation Models (pp. 136-162). Newbury Park, CA: Sage.

Cohen, J., Cohen, P., West, S. G., \& Aiken, L. S. (2003). Applied Multiple Correlation/Regression Analysis for the Behavioral Sciences. London: Taylor \& Francis.

Davidson, R. J., \& Harrington, A. (2002). Visions of Compassion: Western Scientists and Tibetan Buddhists Examine Human Nature. New York: Oxford University Press. https://doi.org/10.1093/acprof:oso/9780195130430.001.0001

DeVellis, R. F. (2012). Scale Development: Theory and Applications. Los Angeles, CA: Sage.

Diener, E. D., Emmons, R. A., Larsen, R. J., \& Griffin, S. (1985). The Satisfaction with Life Scale. Journal of Personality Assessment, 49, 71-75.

https://doi.org/10.1207/s15327752jpa4901_13 
Diener, E., Wirtz, D., Tov, W., Kim-Prieto, C., Choi, D. W., Oishi, S., \& Biswas-Diener, R. (2010). New Well-Being Measures: Short Scales to Assess Flourishing and Positive and Negative Feelings. Social Indicators Research, 97, 143-156. https://doi.org/10.1007/s11205-009-9493-y

Gilbert, P., \& Irons, C. (2004). A Pilot Exploration of the Use of Compassionate Images in a Group of Self-Critical People. Memory, 12, 507-516. https://doi.org/10.1080/09658210444000115

Gilbert, P., \& Procter, S. (2006). Compassionate Mind Training for People with High Shame and Self-Criticism: Overview and Pilot Study of a Group Therapy Approach. Clinical Psychology and Psychotherapy, 13, 353-379. https://doi.org/10.1002/cpp.507

Hair, J., Black, W., Babin, B., \& Anderson, R. (2010). Multivariate Data Analysis (7th ed.). Upper Saddle River, NJ: Prentice-Hall, Inc.

Heffernan, M., Quinn Griffin, M. T., McNulty, S. R., \& Fitzpatrick, J. J. (2010). Self-Compassion and Emotional Intelligence in Nurses. International Journal of Nursing Practice, 16, 366-373. https://doi.org/10.1111/j.1440-172X.2010.01853.x

Homan, K. J. (2016). Self-Compassion and Psychological Well-Being in Older Adults. Journal of Adult Development, 23, 111-119. https://doi.org/10.1007/s10804-016-9227-8

Hu, L. T., \& Bentler, P. M. (1995). Evaluating Model Fit. In R. H. Hoyle (Ed.), Structural Equation Modeling: Concepts, Issues and Applications (pp. 77-99). Thousand Oaks, CA: Sage.

Hu, L. T., \& Bentler, P. M. (1999). Cut-Off Criteria for Fit Indexes in Covariance Structure Analysis: Conventional Criteria versus New Alternatives. Structural Equation Modeling, 6, 1-55. https://doi.org/10.1080/10705519909540118

Jativa, R., \& Cerezo, M. A. (2014). The Mediating Role of Self-Compassion in the Relationship between Victimisation and Psychological Maladjustment in a Sample of Adolescents. Child Abuse \& Neglect, 38, 1180-1190.

https://doi.org/10.1016/j.chiabu.2014.04.005

Jöreskog, K. G., \& Sörbom, D. (1996). LISREL-VI User's Guide (3rd ed.). Moorsville, IN: Scientific Software.

Karakasidou, E., \& Stalikas, A. (2017). The Effectiveness of a Pilot Self-Compassion Program on Well Being Components. Psychology, 8, 538-549.

https://doi.org/10.4236/psych.2017.84034

Karakasidou, E., Pezirkianidis, C., Stalikas, A., \& Galanakis, M. (2016). Standardisation of the Subjective Happiness Scale (SHS) in a Greek Sample. Psychology, 7, 1753-1765. https://doi.org/10.4236/psych.2016.714164

Krieger, T., Altenstein, D., Baettig, I., Doerig, N., \& Holtforth, M. G. (2013). Self-Compassion in Depression: Associations with Depressive Symptoms, Rumination, and Avoidance in Depressed Outpatients. Behavior Therapy, 44, 501-513. https://doi.org/10.1016/j.beth.2013.04.004

Kyriazos, T. (2017). Reliability of Psychometric Instruments. In M. Galanakis, C. Pezirkianidis, \& A. Stalikas (Eds.), Basic Aspects of Psychometrics (pp. 85-121). Athens: Topos.

Kyriazos, T. A., Stalikas, A., Prassa, K., Galanakis, M., Yotsidi, V., \& Lakioti, A. (2018). Psychometric Evidence of the Brief Resilience Scale (BRS) and Modeling Distinctiveness of Resilience from Depression and Stress. Psychology, 9, 1828-1857.

https://doi.org/10.4236/psych.2018.97107

Lovibond, P. F., \& Lovibond, S. H. (1995). The Structure of Negative Emotional States: Comparison of the Depression Anxiety Stress Scales (DASS) with the Beck Depression 
and Anxiety Inventories. Behaviour Research and Therapy, 33, 335-343. https://doi.org/10.1016/0005-7967(94)00075-U

Lyubomirsky, S., \& Lepper, H. S. (1999). A Measure of Subjective Happiness: Preliminary Reliability and Construct Validation. Social Indicators Research, 46, 137-155. https://doi.org/10.1023/A:1006824100041

Mantelou, A., \& Karakasidou, E. (2017). The Effectiveness of a Brief Self-Compassion Intervention Program on Self-Compassion, Positive and Negative Affect and Life Satisfaction. Psychology, 8, 590-610. https://doi.org/10.4236/psych.2017.84038

Neff, K. D. (2003a). The Development and Validation of a Scale to Measure Self-Compassion. Self and Identity, 2, 223-250. https://doi.org/10.1080/15298860309027

Neff, K. D. (2003b). Self-Compassion: An Alternative Conceptualisation of a Healthy Attitude toward Oneself. Self and Identity, 2, 85-101. https://doi.org/10.1080/15298860309032

Neff, K. D. (2009). The Role of Self-Compassion in Development: A Healthier Way to Relate to Oneself. Human Development, 52, 211-214. https://doi.org/10.1159/000215071

Neff, K. D. (2011). Self-Compassion, Self-Esteem, and Well-Being. Social and Personality Psychology Compass, 5, 1-12. https://doi.org/10.1111/j.1751-9004.2010.00330.x

Neff, K. D. (2016). The Self-Compassion Scale Is a Valid and Theoretically Coherent Measure of Self-Compassion. Mindfulness, 7, 264-274. https://doi.org/10.1007/s12671-015-0479-3

Neff, K. D., \& Costigan, A. P. (2014). Self-Compassion, Well-Being, and Happiness. Psychologie in Österreich, 2, 114-119.

http://self-compassion.org/wp-content/uploads/publications/Neff\&Costigan.pdf

Neff, K. D., \& Germer, C. K. (2013). A Pilot Study and Randomised Controlled Trial of the Mindful Self-Compassion Program. Journal of Clinical Psychology, 69, 28-44. https://doi.org/10.1002/jclp.21923

Neff, K. D., \& Vonk, R. (2009). Self-Compassion versus Global Self-Esteem: Two Different Ways of Relating to Oneself. Journal of Personality, 77, 23-50. https://doi.org/10.1111/j.1467-6494.2008.00537.x

Neff, K. D., Bluth, K., Tóth-Király, I., Davidson, O., Knox, M. C., Williamson, Z., \& Costigan, A. (2021). Development and Validation of the Self-Compassion Scale for Youth. Journal of Personality Assessment, 103, 92-105. https://doi.org/10.1080/00223891.2020.1729774

Neff, K. D., Kirkpatrick, K. L., \& Rude, S. S. (2007). Self-Compassion and Adaptive Psychological Functioning. Journal of Research in Personality, 41, 139-154. https://doi.org/10.1016/j.jrp.2006.03.004

Neff, K. D., Rude, S. S., \& Kirkpatrick, K. L. (2007). An Examination of Self-Compassion in Relation to Positive Psychological Functioning and Personality Traits. Journal of Research in Personality, 41, 908-916. https://doi.org/10.1016/j.jrp.2006.08.002

Ozlem, T., Sahin-Baltaci, H., \& Karatas, Z. (2017). Self-Compassion and Communication Skills in Predicting Psychological Help-Seeking Attitudes of Psychological Counsellor Candidates. New Trends and Issues Proceedings on Humanities and Social Sciences, 4, 178-185. https://doi.org/10.18844/prosoc.v4i6.2928

Pauley, G., \& McPherson, S. (2010). The Experience and Meaning of Compassion and Self-Compassion for Individuals with Depression or Anxiety. Psychology and Psychotherapy: Theory, Research and Practice, 83, 129-143.

https://doi.org/10.1348/147608309X471000 
Perez-Blasco, J., Sales, A., Meléndez, J. C., \& Mayordomo, T. (2016). The Effects of Mindfulness and Self-Compassion on Improving the Capacity to Adapt to Stress Situations in Elderly People Living in the Community. Clinical Gerontologist, 39, 90-103. https://doi.org/10.1080/07317115.2015.1120253

Piedmont, R. L. (2014). Inter-Item Correlations. In A. C. Michalos (Ed.), Encyclopedia of Quality of Life and Well-Being Research (pp. 3303-3304). Dordrecht: Springer. https://doi.org/10.1007/978-94-007-0753-5 1493

Psychountaki, M., Zervas, Y., Karteroliotis, K., \& Spielberger, C. (2003). Reliability and Validity of the Greek Version of the STAIC. European Journal of Psychological Assessment, 19, 124. https://doi.org/10.1027//1015-5759.19.2.124

Raes, F. (2010). Rumination and Worry as Mediators of the Relationship between Self-Compassion and Depression and Anxiety. Personality and Individual Differences, 48, 757-761. https://doi.org/10.1016/j.paid.2010.01.023

Raes, F. (2011). The Effect of Self-Compassion on the Development of Depression Symptoms in a Non-Clinical Sample. Mindfulness, 2, 33-36. https://doi.org/10.1007/s12671-011-0040-y

Shapiro, S. L., Brown, K. W., \& Biegel, G. M. (2007). Teaching Self-Care to Caregivers: Effects of Mindfulness-Based Stress Reduction on the Mental Health of Therapists in Training. Training and Education in Professional Psychology, 1, 105-115. https://doi.org/10.1037/1931-3918.1.2.105

Smeets, E., Neff, K., Alberts, H., \& Peters, M. (2014). Meeting Suffering with Kindness: Effects of a Brief Self-Compassion Intervention for Female College Students. Journal of Clinical Psychology, 70, 794-807. https://doi.org/10.1002/jclp.22076

Smith, B. W., Dalen, J., Wiggins, K., Tooley, E., Christopher, P., \& Bernard, J. (2008). The Brief Resilience Scale: Assessing the Ability to Bounce Back. International Journal of Behavioral Medicine, 15, 194-200. https://doi.org/10.1080/10705500802222972

Spielberg, C. D., Edwards, C. D., Lushene, R. E., Montuori, J., \& Platzek, D. (1973). Manual for the State-Trait Anxiety Inventory for Children (STAIC). Palo Alto, CA: Consulting Psychologists Press. https://doi.org/10.1037/t06497-000

Stalikas, A., \& Flora, A. (2012). Depression Anxiety Stress Scale (DASS). In Psychometric Instruments in Greece (2nd ed., p. 247). Athens: Pedio.

Stalikas, A., \& Lakioti, A. (2012). Satisfaction with Life Scale (SWLS). In A. Stalikas, S. Triliva, \& P. Roussi (Eds.), Psychometric Instruments in Greece (p. 752). Athens: Pedio.

Wang, W. L., Lee, H. L., \& Fetzer, S. J. (2006). Challenges and Strategies of Instrument Translation. Western Journal of Nursing Research, 28, 310-321. https://doi.org/10.1177/0193945905284712

Yarnell, L., \& Neff, K. D. (2013). Self-Compassion, Interpersonal Conflict Resolutions, and Well-Being. Self and Identity, 12, 146-159. https://doi.org/10.1080/15298868.2011.649545

Yu, D. S. F., Lee, D. T. F., \& Woo, J. (2004). Issues and Challenges of Instrument Translation. Western Journal of Nursing Research, 26, 307-320.

https://doi.org/10.1177/0193945903260554 